\title{
Sea Surface Salinity: The Next Remote Sensing Challenge
}

\author{
By Gary S.E. Lagerloef, Calvin T. Swift \\ and David M. Le Vine
}

. . the foremost

example of where

sea surface salinity

. . plays an

important role. . .

is the far north

Atlantic.
I IN LATE AUTUmN 1993, a conference on Satellite Altimetry and the Oceans was held in Toulouse, France. The TOPEX/Poseidon satellite had begun the second year in orbit, and all indications were that the data quality was beyond expectations. During the final address at the conference, Carl Wunsch recounted, among other things, the technical progress of satellite altimetry over nearly two decades, wherein the accuracy had improved a 100 -fold. He emphasized that this success resulted from early recognition that fundamental "zerothorder" scientific impact could be derived from planning and implementing requisite technology development. The same has held true for technology to measure winds, sea surface temperature (SST), ocean color, and the gravity field from space, he pointed out, and then asked "What are we overlooking? What new technological challenges are there for zeroth-order impact on the knowledge of the ocean?" The purpose of this paper is to suggest that measuring the global surface salinity field from satellite is the next challenge.

Satellite observations are becoming an integral part of global ocean observing systems designed ultimately to monitor interannual to interdecadal time scale processes as we attempt to understand the uncertainties for forecasting El Niño-Southern Oscillation, global warming, and other climate variations. Perhaps the foremost example of where sea surface salinity (SSS) plays an important role in these processes is the far north Atlantic. Surface low-salinity intrusions are believed to influence the deep convection that drives thermohaline circulation and the meridional heat transport (Dickson et al., 1988; Aagaard and Carmack, 1989; Broecker, 1991; Delworth et al. 1993). The re-

Gary S.E. Lagerloef, Science Applications International Corporation, 13400 Northup Way NE, Bellevue, WA 98005 USA (after 1 July 1995: Earth and Space Research, 10533 Ravenna Ave NE, Seattle, WA 98115, USA). Calvin T. Swift. Microwave Remote Sensing Laboratory. University of Massachusetts, Amherst. MA 01003. USA. David M. Le Vine. Mjcrowave Sensors Branch/Code 975, Laboratory for Hydrospheric Processes, NASA Goddard Space Flight Center, Greenbelt. MD 20771, USA. moteness and harsh climate of the dynamically important regions inhibits conventional measurements making the advantages of an all-weather satellite measurement self-evident.

Salinity variations also influence upper ocean dynamics in the tropics. It has been suggested that upper ocean buoyancy accumulation due to excess rainfall in the western Pacific is a factor in $\mathrm{El} \mathrm{Niño}$ dynamics (Godfrey, 1990). Tropical air-sea heat fluxes are influenced by surface freshened lenses in the heavy rainfall regimes (Lukas and Lindstrom, 1991). For over two decades, the French ORSTOM agency has monitored SSS from several merchant ship tracks in the Pacific, providing perhaps the most comprehensive regional SSS record available. Among other things, these data show that interannual SSS variations are influenced by the precipitation patterns associated with ENSO (Delcroix and Henin, 1991).

The water and heat fluxes associated with precipitation and evaporation over the global ocean are fundamental processes regulating climate and weather. The SSS field, and its seasonal-to-interannual variability, are stringent constraints on the hydrologic balance and coupled ocean-atmosphere climate models. Our knowledge of SSS remains quite limited, however. A census of $1^{\circ} \times 1^{\circ}$ squares shows that $\sim 130 \%$ have no SSS observations at all (Levitus et al., 1994; Table 1) and large expanses are unobserved (Fig. 1). There is an average of about 40 observations per square in those squares with data. Seasonal variations for the world ocean have been estimated (Levitus, 1986) but documenting past interannual-to-interdecadal SSS variability, with the exception of a few longtime series, has not been possible. The situation is improving somewhat with recent world data center acquisitions of previously unavailable historical data sets. However, conventional global SSS observations will not increase significantly in the near future. In contrast, we now possess global satellite measurements of SST, surface topography, winds, and ocean color. The new perspectives on the ocean provided by these data do not need 


\section{Longitude}

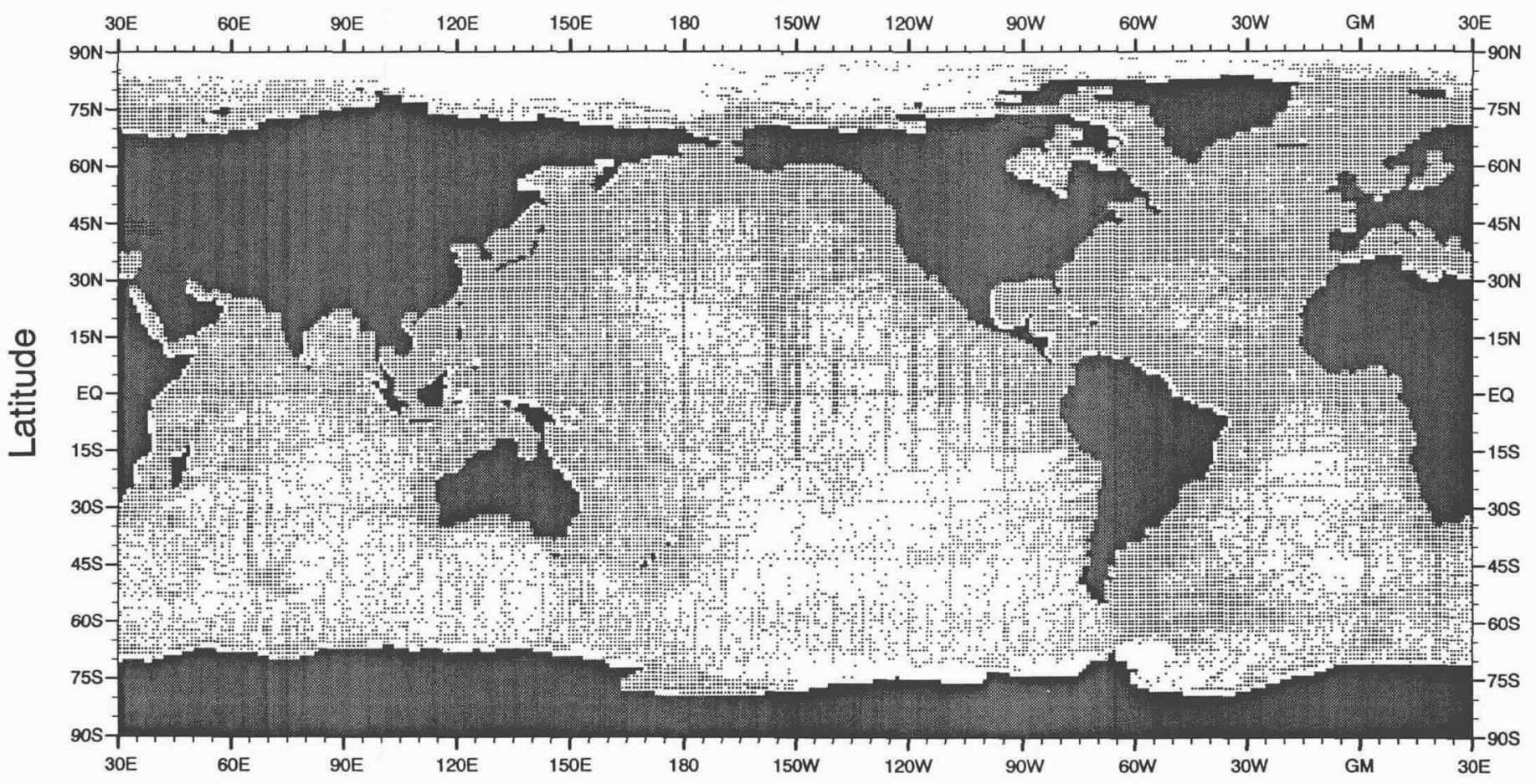

Distribution of salinity observations at the sea surface

\section{Longitude}

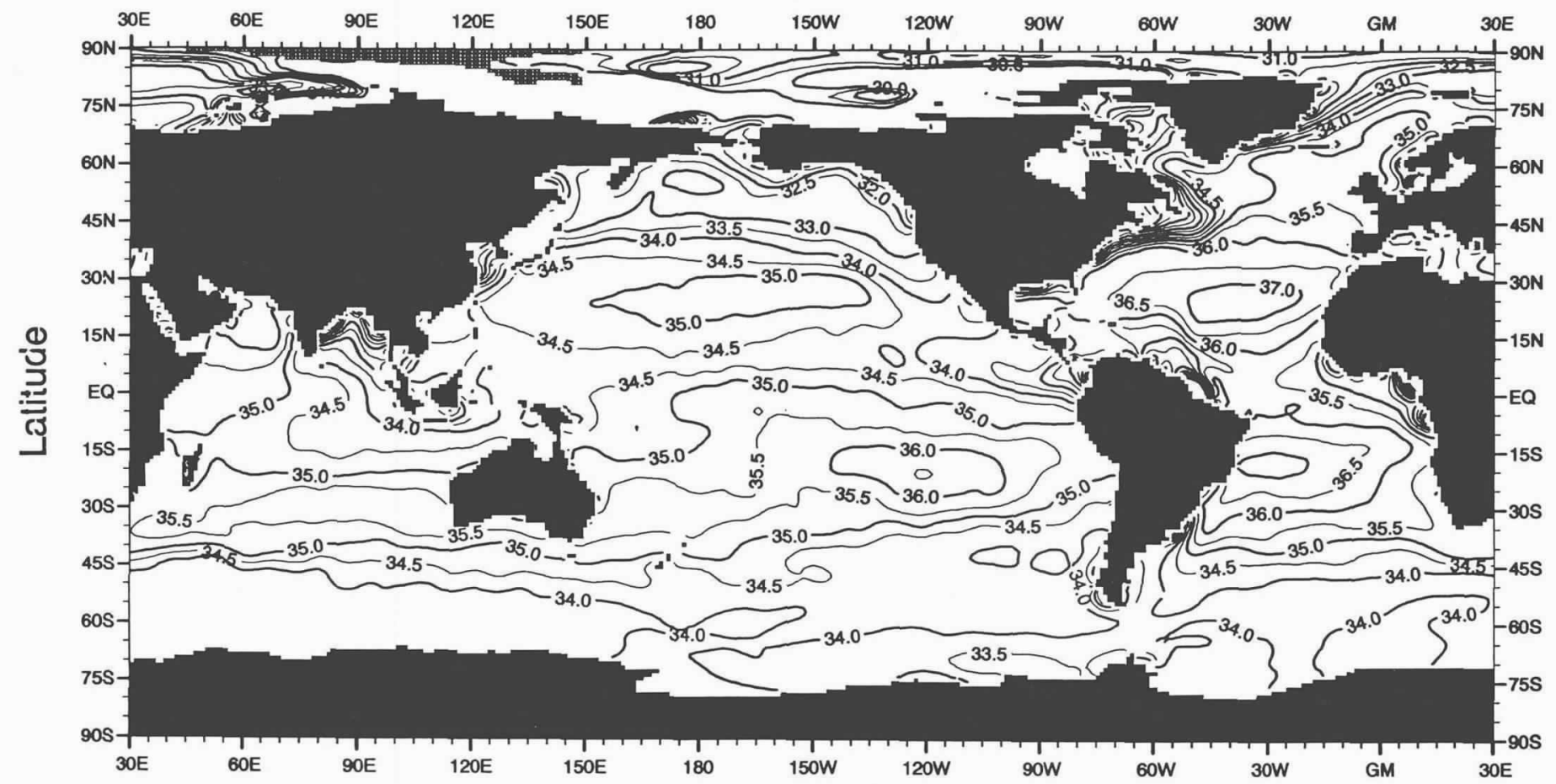

Fig. 1 Top: The present distribution of salinity observations at the surface. Bottom: the mean annual surface salinity field deduced from these observations. (From Levitus et al., 1994.) 
Table 1

ESTAR salinity error budget estimate

\begin{tabular}{|c|c|c|c|c|c|c|}
\hline Error Source & $T_{\mathrm{B}}$ Error, ${ }^{\circ} \mathrm{K}$ & S Error: psu & Length Scale,$+ \mathrm{Km}$ & $\begin{array}{l}\text { Samples (N) per } \\
330 \mathrm{Km} \cdot 10 \mathrm{~d} \%\end{array}$ & $\mathrm{~N}^{1 / 2}$ & Error, psu \\
\hline Sensor $\$$ & 1.0 & 3.0 & 10 & 3250 & 57 & 0.05 \\
\hline SSTH & & 0.3 & 10 & 3250 & 57 & 0.01 \\
\hline Wind & 0.5 & 1.5 & 10 & 3250 & 57 & 0.03 \\
\hline Galactic\# & 0.05 & 0.15 & $10^{3}$ & 3 & 1.7 & 0.09 \\
\hline Ionosphere ${ }^{* * *}$ & 0.05 & 0.15 & $10^{3}$ & 3 & 1.7 & 0.09 \\
\hline Atmosphere $\dagger$ & 0.02 & 0.06 & $10^{3}$ & 3 & 1.7 & 0.03 \\
\hline Total RSS & & & & & & 0.14 \\
\hline
\end{tabular}

* $\partial \mathrm{SSS} / \partial T_{\mathrm{B}}$ at $1.4 \mathrm{GHz}$ ranges from -2 to 4 (Fig. 2) and average value of 3 is assumed.

Length scale same as sensor resolution for ESTAR SST and wind retrievals.

† Assumes 3 satellite passes every $10 \mathrm{~d}$ ( -3 -d repeat) and no subgrid independent samples for long length errors.

$\$$ Sensor accuracy $1^{\circ} \mathrm{K}$ (Swift et al., 1993).

$\|$ Coupled effect of SSS and SST at $1.4 \mathrm{GHz}$ is that $2 \mathrm{SSS} / 2 \mathrm{SST}$ varies from -0.2 to 0.4 and is zero near SST $=15^{\circ} \mathrm{C}$ (Swift and Mclntosh, 1983). Assume magnitude of 0.3 and SST uncertainty of $1^{\circ} \mathrm{C}$.

9 Wind speed relation at $1.4 \mathrm{GHz}$ is estimated between 0.16 and $0.32^{\circ} \mathrm{Km}^{-1}$ s (Webster et al., 1976; Lerner and Hollinger, 1977). Assume $\partial T_{\mathrm{B}} / \partial \mathrm{W}=0.25^{\circ} \mathrm{Km}^{-1} \mathrm{~s}$ and wind speed uncertainty $2 \mathrm{~ms}^{-1}$.

\# Maximum bias at $1.4 \mathrm{GHz}$ is $-1{ }^{\circ} \mathrm{K}$ when galactic core is within $20^{\circ}$ of zenith and otherwise negligible over much of the sky (Blume et al., 1978). Assume correctable to $0.05^{\circ} \mathrm{K}$.

** Maximum ionospheric bias at $1.4 \mathrm{GHz}$ is $\sim 2^{\circ} \mathrm{K}$ in peak daytime conditions and reduced by an order of magnitude at night. This can be corrected with ionosphere models to $<0.05^{\circ} \mathrm{K}$ uncertainty assuming only nighttime observations.

$+\dagger$ Atmosphere corrections at $1.4 \mathrm{GHz}$ vary by $\sim 0.3^{\circ} \mathrm{K}$ over the range of atmospheric conditions (Lemer and Hollinger, 1977 ), and are due mostly to oxygen absorption, which can be corrected with meteorological analyses.

. . the first . . .

attempt to measure

SSS from space took

place 20 years ago

on Skylab. . . repeating here, but it has long been recognized that SSS is an important parameter missing from the satellite remote sensing tool kit. It has been far less recognized that SSS remote sensing is possible and has been demonstrated.

\section{Salinity Remote Sensing-A Brief History, and How It Works}

It may surprise the reader that the first (and only) attempt to measure SSS from space took place 20 years ago on Skylab (Lerner and Hollinger, 1977). A $1.4 \mathrm{GHz}$ microwave radiometer collected data intermittently, there was no "ground truth" other than standard surface charts, and many of the ambient corrections were not as well understood then as they are today. Nevertheless, a correlation was found between the sensor data (after correcting for other influences) and SSS. This was an encouraging early result.

The research leading up to the Skylab experiment began with several efforts during the late 1940 s and early 1950 s to measure the complex dielectric constant of saline solutions for various salinities, temperatures, and microwave frequencies. These relationships provide the physical basis for microwave remote sensing of the ocean. In brief, the ocean radiometric brightness temperature $\left(T_{B}\right)$ is related to the absolute thermodynamic temperature $(T)$ by the emissivity $(e)$ as

$$
T_{B}=e T
$$

The emissivity is a complex function of the dielectric constant of seawater, viewing angle, polarization, and other factors. The dielectric constant, in turn, is governed by the electrical conduc- tivity and the microwave frequency of observation. Since conductivity is governed by salinity and temperature, $T_{B}$ can be expressed as a function of SSS and SST, although the equations are quite complicated; Klein and Swift (1977) and Swift and McIntosh (1983) give a detailed discussion. At relatively low microwave frequencies $\sim 1$ to 3 $\mathrm{GHz}$ the sensitivity is sufficient to permit SSS remote sensing. Figure 2 shows the $T_{B}$ model function at 1.43 (L-band) and 2.65 (S-band) $\mathrm{GHz}$ for zero incidence (nadir view). The $T_{B}$ relation with SSS and SST differs at these two frequencies, and it is possible to obtain both SSS and SST with dual frequency measurements (Blume et al., 1978). Furthermore, atmospheric water and ice clouds have a negligible effect at these frequencies, and the observations are possible in all weather.

Droppelman et al. (1970) demonstrated the first airborne salinity measurements in the Mississippi River outflow. This led to renewed efforts to refine the dielectric constant and governing equations with application to ocean remote sensing (Klein and Swift, 1977). Meanwhile, a series of airborne experiments followed Skylab and mapped coastal salinity patterns in the Chesapeake and $\mathrm{Sa}-$ vannah river plumes and along the Puerto Rico shoreline. (Blume et al., 1978 and 1981; Blume and Kendall, 1982; Kendall and Blanton, 1981). Swift and McIntosh (1983) described a satellite concept with an ideal precision of $\sim 0.25$ practical salinity units (psu; equivalent to parts per thousand) and spatial resolution of $\sim 100 \mathrm{~km}$. They reviewed a number of measurement and technical issues needing study. These issues remain, but 


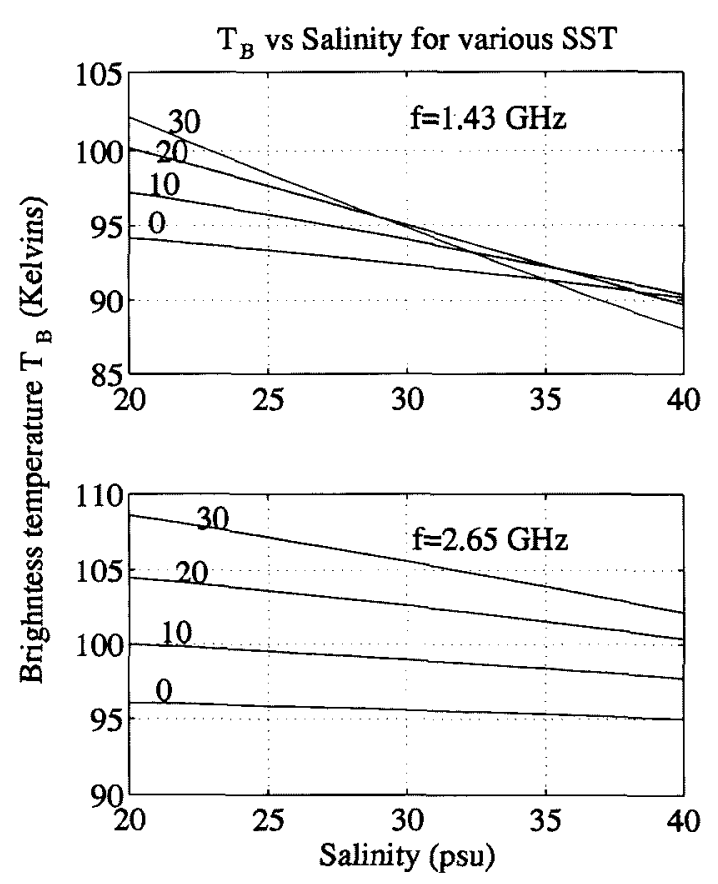

Fig. 2: The variation of brightness temperature due to salinity at $1.4 \mathrm{GHz}$ and $2.65 \mathrm{GHz}$, with SST as a parameter, according to the formulas given by Klein and Swift (1977).

reasonable estimates of their influence on measurement accuracy can be made (see below). It was becoming evident that satellite SSS remote sensing was a possibility.

In the early 1980 s, NASA was in the process of establishing the oceanic processes remote sensing program around a package of missions and sensors for measuring dynamic topography, wind stress, ocean color, SST, and sea ice. Salinity remote sensing was considered, but there was a tendency to view it in the context of $\sim 1 \mathrm{~km}, 1^{\circ} \mathrm{C}$ infrared SST capability. As shown below, such a program would require enormous antenna structures, and the measurement accuracy would not rival that of SST. Oceanographers accustomed to making highprecision salinity measurements at sea concluded that remote sensing data quality did not justify a dedicated effort. This, coupled with the lack of a clearly defined scientific need for the data at the degraded accuracy and resolution, prompted the decision to abandon SSS remote sensing and focus on the other elements of the ocean program.

Interest in SSS remote sensing revived in the late 1980 s with the development of a $1.4 \mathrm{GHz}$ airborne Electrically Scanning Thinned Array Radiometer (ESTAR). ESTAR imaging is done electronically with no moving antenna parts, thus making larger antenna structures more feasible. The airborne version was developed as an engineering prototype and to provide the proof-of-concept that aperture synthesis can be extrapolated to a satellite design (Le Vine et al., 1990). On a few occasions there have been opportunities to collect ocean data with this sensor; results from a flight across the Gulf Stream near Cape Hatteras are shown in Figure 3. The change from $\mathrm{SSS}>36$ in the offshore waters to $\mathrm{SSS}<32$ near shore is evident, along with several frontal features noted in the satellite SST image from the same day (not shown). The Gulf Stream transect suggests that smaller open ocean variations can be detected as well as the strong salinity gradients in the coastal and estuary settings demonstrated previously. In fact, development of a sensor to be routinely carried on commercial aircraft to monitor SSS along routes crossing the subpolar North Atlantic has been proposed. At this point, however, we wish to focus our discussion on satellite measurements.

\section{ESTAR-A New Mission Concept}

Circumstances have evolved to where we should reconsider the choices made a decade ago regarding salinity remote sensing. First, the scientific agenda has changed. Long-term commitments for the existing ocean remote sensing measurements are gradually falling into place. It is time to examine which new applications and parameters should next be addressed. Coupled with this are the scientific developments, alluded to above, which have stimulated interest in measuring surface salinity. Second, the new ESTAR technology implies that spatial resolution can be significantly improved at these low frequencies, which in turn removes a major limitation on measurement precision, given that random errors can be reduced by averaging over larger areas.

Improving spatial resolution requires the larger antenna size that is made practical with ESTAR. A radiometer footprint size $(x)$ is determined by the electromagnetic wavelength $(\lambda)$, satellite altitude $(h)$ and antenna aperture $(D)$ as follows:

$$
x \approx 1.22 \frac{\lambda h}{D}
$$

With ESTAR it is feasible to deploy a $\sim 10 \mathrm{~m}$ aperture antenna to obtain $10-\mathrm{km}$ resolution from an orbit altitude of $\sim 400 \mathrm{~km}$ for a $1.4-\mathrm{GHz}(\lambda=$ $21 \mathrm{~cm}$ ) radiometer (see Swift, 1993 for more technical detail). In contrast to achieving a $10-\mathrm{km}$ footprint, it would still require an enormous (and unfeasible) antenna to obtain $\sim 1-\mathrm{km}$ resolution. We should dispel any misconceptions that spaceborne salinity remote sensing will ever provide the rich detail of surface processes evident in SST images. Instead, we should adjust our thinking and evaluate if scientifically useful measurements can be obtained at larger spatial scales. A clue to defining those scales can come from other satellite projects.

\section{Comparing SSS With Other Satellite Measurements}

The Special Sensor Microwave Imager (SSMI) operates at frequencies from 18 to $85 \mathrm{GHz}$, where the $T_{B}$ variations caused by atmospheric water
Circumstances have

evolved to where we should reconsider the choices made a decade ago regarding salinity remote sensing. 
Salinity from NASA P-3 ESTAR April 1991

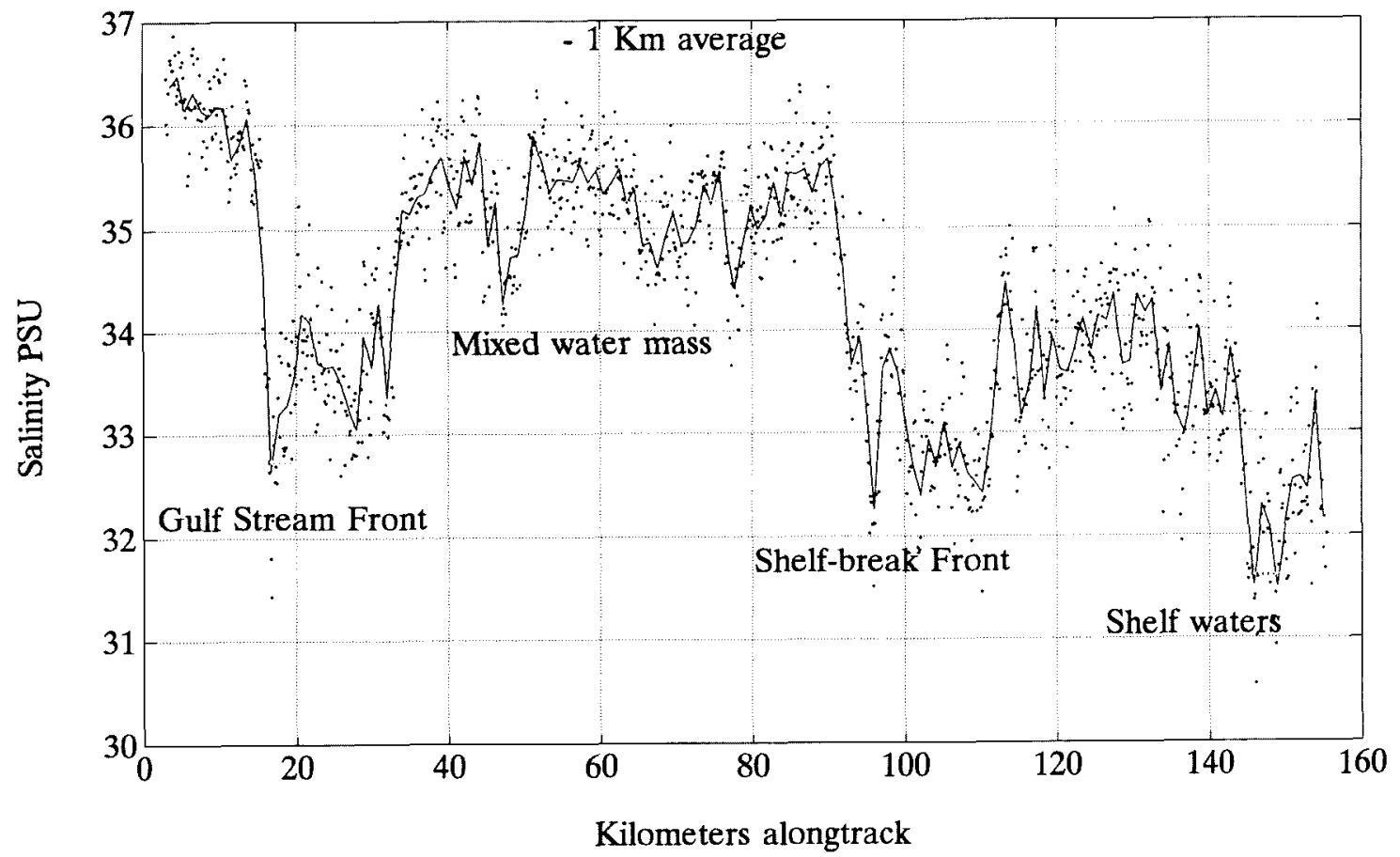

Fig. 3: Salinity measurements with the airborne ESTAR along a transect from seaward of the Gulf Stream to Cape Hatteras, April 1991. The SSS change from $>36$ in the offshore waters to $<32$ in coastal waters is evident, along with several frontal features noted in the satellite SST image from the same day (not shown). Points are 1 -s averages and the solid line is $1 \mathrm{~km}$ along-track averages $(\sim 7 \mathrm{~s})$.

... experienced

remote sensing

scientists take a

skeptical view of

salinity remote

sensing using a

microwave radiometer

with $\mathrm{a} \sim 1^{\circ} \mathrm{K}$ sensor

error. vapor and rainfall cover dynamic ranges of $\sim 100^{\circ} \mathrm{K}$, and a sensor error of $1^{\circ} \mathrm{K}$ provides very good parameter resolution. We can see from Figure 2 that at $1.4 \mathrm{GHz}$ the $T_{B}$ range is only $-5^{\circ} \mathrm{K}$ over open ocean conditions (remote from coastal regions). It is no wonder that experienced remote sensing scientists take a skeptical view of salinity remote sensing using a microwave radiometer with a $\sim 1^{\circ} \mathrm{K}$ sensor error. However, oceanic time scales are generally much slower than the atmospheric synoptic scale, and sampling requirements can be relaxed. TOPEX/Poseidon, for example, measures ocean dynamic topography in an orbit that traces a diamond-shaped lattice grid repeated every $10 \mathrm{~d}$ (Fig. 4). The area of one grid cell at low latitude is about $110,000 \mathrm{~km}^{2}$ or the equivalent of a $\sim 330-\mathrm{km}$ square. It is instructive to compare the capabilities of TOPEX/Poseidon at this spatial and temporal resolution with a salinity sensor such as ESTAR to assess the scientific potential of the latter. The sampling density would increase with latitude commensurately for both satellites, so $330-\mathrm{km}$ resolution can be used as a general basis for comparison. Table 1 shows summaries of the estimated salinity measurement errors and the impact of error reduction through spatial and temporal averaging. It is assumed that the sensor is in a sun-synchronous orbit with a revisit time of $\sim 3 \mathrm{~d}$, measures SSS at $10-\mathrm{km}$ resolution each pass, and carries channels to measure SST and wind at the same resolution (see Swift et al., 1993). It is immediately apparent that the sensor noise is the largest error source at the fine scale $(10 \mathrm{~km})$, but is a minor term on the large scales due to averaging. The long length scale errors do not have this advantage and represent the largest uncertainties needing to be modeled and corrected. Reasonable estimates of the uncertainties after correction are given in the table and notes, and the total root sum square (rss) error is estimated to be $\sim 0.14$ psu at these scales.

Table 2 shows a comparison to TOPEX/Poseidon. The mean dynamic topography has a dynamic range of $-250 \mathrm{~cm}$ globally and, with a $\sim 5$-cm error, TOPEX/Poseidon yields a $\sim 50: 1$ signal-to-error ratio. Open ocean surface salinity varies from 32 to $37 \mathrm{psu}$ globally, for a $5 \mathrm{psu} \mathrm{dy}$ namic range. We see that a $\sim 0.14$ psu rss error

Table 2

Performance comparison

\begin{tabular}{lcl}
\hline & TOPEX/Poseidon & ESTAR Salinity \\
\hline Spatial resolution & $330 \mathrm{Km}$ & $330 \mathrm{Km}$ \\
Temporal resolution & $10 \mathrm{~d}$ & $10 \mathrm{~d}$ \\
Signal dynamic range & $250 \mathrm{~cm}$ & $5 \mathrm{psu}$ \\
Error & $5 \mathrm{~cm}$ & $0.14 \mathrm{psu}$ \\
Signal to error ratio & $50: 1$ & $35: 1$ \\
\hline
\end{tabular}


suggests that a comparable $\sim 35: 1$ signal-to-error ratio is possible for SSS measurements at the same spatial and temporal scales as TOPEX/Poseidon. Even with larger errors, say $\sim 0.25 \mathrm{psu}$, the signalto-error ratio would be on the same order. Other altimeter mission (ERS1, Geosat) signal-to-error ratios are likewise smaller than TOPEX/Poseidon, and the scientific value of those missions is well recognized. There are a number of assumptions in the error estimates of Table 1, so it would be more prudent, perhaps, to consider these as reasonable technical objectives. We can add some margin here by giving a range, say of 0.1 to 0.3 psu error on length scales of 100 to $300 \mathrm{~km}$ and periods of weeks to months. Quite honestly, we cannot be more specific without further engineering study. Nevertheless, salinity remote sensing has significant promise at the resolution scales of satellite altimetry. In terms of global observations, we see a simple trade-off between sparse yet very accurate conventional salinity measurements versus much less accurate data with much more dense and orderly sampling from satellite. At $10-\mathrm{km}$ resolution and 3-day repeat sampling, about 1,000 samples per 1-degree square can be obtained per month. Consider this in comparison to Figure 1, which is the present day accumulation of all historical data. Large ocean expanses, particularly in the Southern Hemisphere, would be observed for the first time. Remote sensing can provide a vast amount of new information, even with a signal-tonoise ratio of order 1 . The ocean salinity spectrum is red, and assuming the error noise is white, there exists a time and space scale where the signal will emerge. With appropriate emphasis on technology, rudimentary signal processing and careful attention to modeling the requisite corrections to the data, it will be possible to measure SSS usefully on climatic scales. Absolute calibration and monitoring of instrument drift could be done, the same way we presently do SST remote sensing, with surface observations from a variety of conventional platforms such as drifters, moorings and volunteer ships.

\section{Conclusion}

We have sought to convince the reader that SSS satellite remote sensing is a practical idea. There are some who will argue that the error estimates given here are unrealistic. The counter argument is that errors can be significantly reduced with proper commitment of resources to the technology. Salinity remote sensing carries no more technical risk than other well-known remote sensing techniques did in their infancy. Advancing technology always generates improvements. It is instructive to recall the accuracy of the earliest dedicated altimeter mission (GEOS-3), nearly 20 years ago, in which the radial orbit error was many meters and the altimeter noise level was $\sim 50 \mathrm{~cm}$. TOPEX/Poseidon has cut those errors by about two orders of magnitude and now measures
TOPEX/Poseidon Ground Track

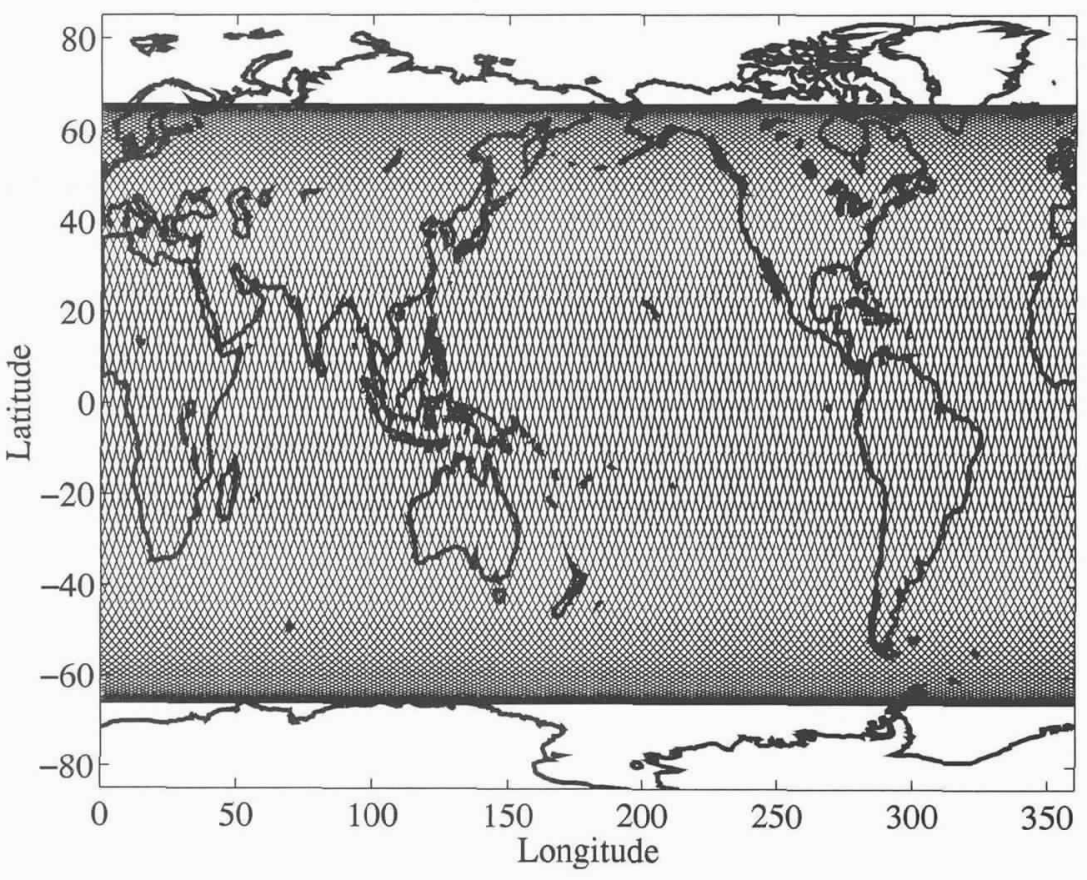

Fig. 4: The TOPEX/Poseidon radar altimeter satellite ground track measuring dynamic height variability with an error of about $5 \mathrm{~cm}$. The orbit is repeated every $10 \mathrm{~d}$, and the area of the grid spaces is approximately equal to a $330-\mathrm{km}$ square at the equator. We estimate the potential accuracy of an ESTAR salinity measurement to be $\sim 0.14 \mathrm{psu}$ if data at $10-\mathrm{km}$ resolution and 3-d repeat are averaged to the TOPEX/Poseidon spatial and temporal resolution (see text). An ESTAR orbit would extend to about $82^{\circ}$ latitude.

global sea level to an accuracy of $\sim 5 \mathrm{~cm}$. SSS remote sensing is technically feasible and can deliver a precision of $0.1-0.3$ psu on a spatial scale of about $100-300 \mathrm{~km}$ and a time scale of weeks to months.

Such a global data set would significantly advance climate research and provide data from large ocean regions presently unobserved. Global SSS monitoring would provide data to help close the hydrologic budget and constrain coupled climate models, monitor the upper ocean response to precipitation variability in the tropical convergence, and provide early detection of low-salinity intrusions in the subpolar Atlantic and Southern oceans. For example, the surface anomalies described by Dickson et al., (1988) ranged from 0.1 to $1.0 \mathrm{psu}$ on interannual time scales. The above analyses suggest that such variations would be detectable by a satellite sensor such as ESTAR and traceable over the evolution of the multi-year event. Such monitoring would allow years of advance notice to plan observations of the ensuing thermohaline variations as they propagate through intermediate and deep North Atlantic waters (e.g., Levitus, 1989; Delworth et al., 1993).

It should be noted that much of the original motive for the ESTAR development came from requirements to measure soil moisture (Le Vine et al., 1992). A significant effort has gone into devel-
. . salinity remote

sensing has

significant promise

at the resolution

scales of satellite

altimetry. 
oping models for $1.4 \mathrm{GHz}$ soil moisture measurements, which have a much wider $T_{B}$ dynamic range $\left(\sim 100^{\circ} \mathrm{K}\right)$ than salinity (Jackson et al., 1982). An ad hoc technical review of ESTAR was convened in 1992 by NASA. The report recommended exploring an economical ESTAR satellite mission with the lesser restriction on accuracy demanded by soil moisture. Salinity requirements were considered too costly, but the report noted that data from a soil moisture mission should certainly be analyzed for salinity. A simplified $1.4 \mathrm{GHz}$ sensor would lack the additional channels to correct for SST and wind over the ocean. In this case the requisite corrections could be obtained from operational and climate data bases, as well as Earth Observing System (EOS) sensors which will provide all-weather wind and SST data at useful resolution. Notwithstanding, a $1.4 \mathrm{GHz}$ single-channel sensor with the $1^{\circ} \mathrm{K}$ accuracy requirement for soil moisture would serve as an important experiment to measure SSS. We see that an ESTAR mission can serve the needs of surface hydrology for most of the earth surface, providing surface data over land as well the ocean. Many of us recognize that the present funding climate is not favorable to new mission proposals, and ESTAR is not being actively promoted presently within NASA. Successful programs now often require support from several agencies or nations and need interdisciplinary scientific advocacy. As in the past, this implies broad recognition of the potential for new knowledge the measurements can provide and a commitment to develop the necessary technology. To move ESTAR forward, interested scientists must be made aware of its possibilities and become vocal advocates for serious consideration by the agencies. Our purpose here has been to give a candid assessment of the present state of the technology as a first step in that process.

\section{References}

Aagaard, K. and E.C. Carmack, 1989: The role of sea ice and other fresh water in the Arctic circulation. J. Geophys. Res., 94, 14,485-14,498.

Blume. H-J.C., B.M. Kendall and J.C. Fedors, 1978: Measurement of ocean temperature and salinity via microwave radiometry. Bound. Layer Meteor., 13, 295-380.

B.M. Kendall and J.C. Fedors, 1981: Multifrequency radiometer detection of submarine freshwater sources along the Puerto Rican coastline. J. Geophys. Res., 86, $5283-5291$

, and B.M. Kendall, 1982: Passive microwave measurements of temperature and salinity in coastal zones. IEEE Trans. Geosci. Rem. Sens., GE-20, 394404.

Broecker, W.S., 1991: The great ocean conveyer. Oceanogra- phy, 4, 79-89.

Delcroix, T. and C. Henin, 1991: Seasonal and interannual variations of sea surface salinity in the tropical Pacific Ocean. J. Geophys. Res. 96, 22,135-22,150.

Delworth, T., S. Manabe and R.J. Stouffer, 1993: Interdecadal variations of the thermohaline circulation in a coupled ocean-atmosphere model. I. Climate, 6. 1993-2011.

Dickson, R.R., R. Meincke, S.-A. Malmberg and J.J. Lee, 1988: The "Great Salinity Anomaly" in the Northern North Atlantic, 1968-1982. Prog. Oceanogr., 20. $103-151$.

Droppelman, J.D., R.A. Mennella and D.E. Evans, 1970: An airbome measurement of the salinity variations of the Mississippi River outflow. J. Geophys. Res., 75. $5909-5913$.

Godfrey, J.S., 1990: Salinity Monitoring Project Report. In: JSC/CCCO TOGA Scientific Steering Group Report of the Eighth Session, Appendix C, WCRP-31, WMORDNo. 338, World Meteorological Organization, Geneva.

Jackson, T.J. T.J. Schmugge and J.R. Wang, 1982: Passive microwave remote sensing of soil moisture under vegetation canopies. Water Resour. Res., 18. 1137-1142.

Kendall, B.M. and J.O. Blanton, 1981: Microwave radiometer measurement of tidally induced salinity changes off the Georgia coast. J. Geophys. Res., 86, 6435-6441.

Klein, L.A. and C.T. Swift, 1977: An improved model for the dielectric constant of sea water at microwave frequencies. IEEE Trans. Antemas and Propag. AP-25. 104-111.

Lerner. R.M. and J.P. Hollinger. 1977: Analysis of $1.4 \mathrm{GHz}$ radiometric measurements from Skylab. Remote Sens. Envinon., 6. 251-269.

Le Vine, D.M., M. Kao, A.B. Tanner, C.T. Swift and A. Griffis, 1990: Initial results in the development of a synthetic aperture radiometer. IEEE Trans. Geosci. Rem. Sens., 28, 614-619.

A. Griffis, C.T. Swift and T.J. Jackson. 1992: ESTAR: A synthetic aperture microwave radiometer for measuring soil moisture. In: Proceedings IGARSS-92. vol. II, Houston, TX, 1755-1757.

Levitus, S., 1986: Annual cycle of salinity and salt storage in the World Ocean. J. Phys. Oceanog., 16, 322-343.

1989: Interpentadal variability of temperature and salinity at intermediate depths of the North Atlantic Ocean. 1970-1974 versus 1955-1959. J. Geophys. Res.. 94, 6091-6131.

R. Burgett and T.P. Boyer, 1994: NOAA Atlas NESDIS 3, World Ocean Allas 1994 Volume 3: Salinity, U.S. Dept. Commerce, Washington, DC, 99 pP.

Lukas, R. and E. Lindstrom, 1991: The mixed layer of the western equatorial Pacific Ocean. J. Geophys. Res., 96. 3343-3357.

Swift, C.T. and R.E. McIntosh, 1983: Considerations for microwave remote sensing of ocean-surface salinity. IEEE Trans. Geosci. Rem. Sens., GE-2J, 480-491.

1993: ESTAR-The Electronically Scanned Thinned Array Radiometer for remote sensing measurement of soil moisture and ocean salinity. NASA Technical Memorandum 4523, $40 \mathrm{pp}$.

Webster, W.J., T. Wilheit, D. Ross and P. Gloersen, 1976 : Spectral characteristics of the microwave emission from a wind-driven foam-covered sea. J. Geophys. Res., 81, 3095-3099. $\square$ 